\title{
Clinical Predictors for Neutrophil-to-Lymphocyte Ratio Changes in Patients with Chronic Hepatitis B Receiving Peginterferon Treatment
}

\author{
PUO-HSIEN LE ${ }^{1,2}$, KUNG-HAO LIANG ${ }^{1,3}$, MING-LING CHANG $^{1,2}$, CHAO-WEI HSU $^{1,2}$, YI-CHENG CHEN ${ }^{1,2}$, \\ CHIH-LANG LIN ${ }^{1,2}$, WEY-RAN LIN ${ }^{1,2}$, MING-WEI LAI ${ }^{1,2}$ and CHAU-TING YEH YH $^{1,2,3}$ \\ ${ }^{1}$ Liver Research Center, Linkou Chang Gung Memorial Hospital, Taoyuan, Taiwan, R.O.C.; \\ ${ }^{2}$ Department of Gastroenterology and Hepatology, \\ Linkou Chang Gung Memorial Hospital, Taoyuan, Taiwan, R.O.C.; \\ ${ }^{3}$ Molecular Medicine Research Center, Chang Gung University, Taoyuan, Taiwan, R.O.C.
}

\begin{abstract}
Background: A lower neutrophil-to-lymphocyte ratio (NLR) was found to be associated with better clinical outcomes in hepatitis B-related liver cirrhosis and hepatocellular carcinoma. We aimed to identify pretherapeutic variables capable of predicting NLR changes in patients with hepatitis $B$ receiving peginterferon therapy. Patients and Methods: The baseline clinicopathological data were analyzed to correlate with NLR changes before and 1 year after peginterferon treatment in 71 patients with hepatitis B. Results: Univariate analysis revealed that pretreatment NLR itself negatively predicted NLR changes following peginterferon treatment (odds ratio $(O R)=0.320$, $p=0.013)$. Further analysis identified pre-treatment NLR, hemoglobin and hepatitis $B$ surface antigen level as independent predictors for NLR changes (adjusted $p=0.028,0.005$, and 0.028 , respectively). A predictive score composed of these three factors had an area under the curve of $76.5 \%(p<0.001)$. Conclusion: Pretreatment NLR, hemoglobin and hepatitis $B$ surface antigen level in combination, effectively predicted NLR changes following peginterferon treatment.
\end{abstract}

Hepatitis B virus (HBV) infection is a global public health issue. There are about 250 million HBV carriers in the world, of whom roughly 600,000 die annually from HBV-

This article is freely accessible online.

Correspondence to: Chau-Ting Yeh, Liver Research Center, Chang Gung Memorial Hospital, 199, Tung Hwa North Rd, Taipei, Taiwan, R.O.C. E-mail: chautingy@gmail.com

Key Words: Neutrophil-to-lymphocyte ratio, chronic hepatitis B, peginterferon. related liver disease, including liver cirrhosis and hepatocellular carcinoma (HCC) (1-4). Interferon and nucleos(t)ide analogs are two major classes of antiviral therapies against $\mathrm{HBV}$. Both are capable of reducing the incidence of HCC (5-8). In view of HCC prevention, peginterferon remains superior to nucleos(t)ide analogs (9). One possible reason for this is the emergence of $\mathrm{HBV}$ surface antigen truncation mutations, which had increased oncogenic potentials, in patients receiving long-term nucleos(t)ide analogue therapy (9-11) and the other is the immunomodulatory properties of peginterferon, which is believed to exert anticancer effect (12).

One of the major contributing factors for HCC development, recurrence and metastasis is the imbalance of inflammatory response (13-15). Several indicators of systemic inflammation, such as C-reactive protein, neutrophil-to-lymphocyte ratio (NLR), lymphocyte-to-monocyte ratio, platelet-to-lymphocyte ratio (PLR) and modified Glasgow prognostic score have been used for evaluation of inflammatory status. Neutrophils and lymphocytes are the essential components of the tumor-related stroma, and are closely correlated to local inflammation and immune responses (16). Because blood neutrophil and lymphocyte counts are routinely checked during clinical practice, NLR is widely used as a reference for immunological status of the patients (17). Nowadays, a higher NLR has been correlated with poorer prognosis in several malignancies (1823 ), including resectable and advanced HCC (24-26). In this way, lower NLR seems to imply a lower risk and better outcome of HCC in chronic HBV-infected patients. We, therefore, hypothesized that the NLR change post peginterferon treatment might provide an explanation for its superior HCCprevention effect. Searching the literature, there is no study focusing on the change of NLR after peginterferon treatment in chronic hepatitis B patients. In this study, we aimed to clarify this important issue. 


\section{Patients and Methods}

Patients. Under the approval of the Chang Gung Medical Foundation Institutional Review Board, we retrieved the clinical data of 123 patients with chronic hepatitis B, who underwent liver biopsy as part of pretreatment evaluations between 2007 and 2009. Of them, 52 patients either did not receive any antiviral treatments or received only nucleos(t)ide analogues therapy. These patients were excluded. The remaining 71 patients were treated with peginterferon and were enrolled into this study. All participants were given written informed consent. Baseline pretreatment data were reviewed, which included age, gender, liver cirrhosis, Ishak histology activity indexes (27), HBV DNA level, HBV e antigen ( $\mathrm{HBeAg}$ ), quantitative HBV surface antigen (HBsAg) level, alanine transaminase (ALT), aspartate transaminase (AST), bilirubin, platelet count, hemoglobin $(\mathrm{Hb})$, total white blood cell count (WBC), neutrophil count, lymphocyte count, neutrophil percentage, lymphocyte percentage, NLR, and PLR. Post-treatment data ( $>1$ year after the end of treatment) included total WBC count, neutrophil count, lymphocyte count, neutrophil percentage, lymphocyte percentage, NLR, and PLR. Diagnosis of HCC was made by liver biopsy or aspiration cytology; if tissue-based diagnosis could not be performed due to patients' conditions, dynamic computed tomography and angiography with an alpha-fetoprotein level of $>200$ $\mathrm{ng} / \mathrm{ml}$ were used as diagnostic criteria $(28,29)$. HBV DNA levels were measured by COBAS TaqMan HBV test (Roche Molecular Systems, Branchburg, NJ, USA). Quantitation of the HBsAg level was assessed using the Elecsys HBsAg II assay (Roche Diagnostics, Indianapolis, IN, USA). Patients were followed up for at least 5 years after the pretreatment biopsy.

Antiviral treatments. All enrolled patients were treated with peginterferon alfa-2a (Pegasys, Roche, Basel, Switzerland), including those who were treated with peginterferon monotherapy $(n=37)$ and those who were also treated with nucleos(t)ide analogs before, during, or after the peginterferon therapy $(n=34)$. In HBeAgpositive patients, peginterferon was given for at least 6 months, and in $\mathrm{HBeAg}$-negative patients, peginterferon was given for at least 1 year. The treatments were administered according to Asian Pacific Association for the Study of the Liver (APASL) guidelines (30).

Statistical analysis. Numerical data are presented as mean \pm standard deviation, while categorical data are expressed as absolute numbers and percentages. Immunological changes after peginterferon treatment were evaluated by paired $t$-test, and shown as mean \pm standard deviation and $p$-value. Univariate and multivariate analyses were performed by linear regression to identify independent factors for post-treatment NLR. The results are presented as regression coefficient (B), with 95\% confidence interval (CI) and $p$-value. We used logistic regression to evaluate clinical factors associated with binary NLR change. In this part, if a continuous variable had a $p$-value of less than 0.3 , we modified it into a dichotomous variable for further analysis by use of the optimal cutoff points decided by receiver operating characteristic (ROC) curves with Youden index for better clinical application. The results are presented as odd ratios (OR), with $95 \% \mathrm{CI}$ and $p$-value. The results were considered to indicate a statistically significant difference when $p$-value less than 0.05 . All statistical calculations were performed using SPSS software, version 21 (IBM, Armonk, NY, USA).
Table I. Baseline characteristics.

\begin{tabular}{|c|c|}
\hline Characteristic & Value $(n=71)$ \\
\hline Age, years & $39.14 \pm 10.33$ \\
\hline \multicolumn{2}{|l|}{ Gender, n (\%) } \\
\hline Male & $60(84.5 \%)$ \\
\hline Female & $11(15.5 \%)$ \\
\hline Cirrhosis, $\mathrm{n}(\%)$ & $16(22.5 \%)$ \\
\hline Ishak histology activity index & $3.01 \pm 1.43$ \\
\hline Piecemeal necrosis (score $>1$ ) & $12(16.9 \%)$ \\
\hline Confluent necrosis (score $>0)$ & $7(9.9 \%)$ \\
\hline $\begin{array}{l}\text { Focal (spotty) lytic necrosis, apoptosis, } \\
\text { and focal inflammation (score }>2 \text { ) }\end{array}$ & $15(21.1 \%)$ \\
\hline Portal inflammation (score $>2$ ) & $30(42.3 \%)$ \\
\hline \multicolumn{2}{|l|}{ Viral serological analysis } \\
\hline HBV DNA load, $\log _{10} \mathrm{IU} / \mathrm{ml}$ & $7.09 \pm 1.34$ \\
\hline $\mathrm{HBeAg}$ positive & $49(69 \%)$ \\
\hline HBsAg level, $\log _{10} \mathrm{IU} / \mathrm{ml}$ & $3.65 \pm 0.88$ \\
\hline \multicolumn{2}{|l|}{ Other laoratory analysis } \\
\hline ALT, IU/1 & $157.41 \pm 133.05$ \\
\hline AST, IU/1 & $91.64 \pm 79.63$ \\
\hline Bilirubin, mg/dl & $0.91 \pm 0.29$ \\
\hline Platelet count, $\times 1000 / \mathrm{mm}^{3}$ & $198.25 \pm 43.37$ \\
\hline Hemoglobin, g/dl & $15.12 \pm 1.37$ \\
\hline \multicolumn{2}{|l|}{ Pre-treatment immunological status } \\
\hline Total white blood cell count, $/ \mu 1$ & $5697.18 \pm 1541.98$ \\
\hline Neutophil count, $/ \mu \mathrm{l}$ & $2919.82 \pm 1005.35$ \\
\hline Lymphocyte count, / $\mu 1$ & $2209.55 \pm 766.86$ \\
\hline Neutrophil percentage, $\%$ & $51.05 \pm 8.92$ \\
\hline Lymphocyte percentage, $\%$ & $38.91 \pm 8.57$ \\
\hline NLR & $1.44 \pm 0.63$ \\
\hline PLR & $100.00 \pm 38.22$ \\
\hline \multicolumn{2}{|l|}{ Post-treatment immunological status } \\
\hline Total white blood cell count, $/ \mu \mathrm{l}$ & $5660.00 \pm 1301.44$ \\
\hline Neutophil count, $/ \mu \mathrm{l}$ & $2976.69 \pm 846.47$ \\
\hline Lymphocyte count, $/ \mu \mathrm{l}$ & $2114.87 \pm 732.35$ \\
\hline Neutrophil percentage, $\%$ & $52.92 \pm 9.36$ \\
\hline Lymphocyte percentage, $\%$ & $37.32 \pm 8.70$ \\
\hline NLR & $1.58 \pm 0.78$ \\
\hline PLR & $102.14 \pm 46.07$ \\
\hline
\end{tabular}

Data are mean value \pm standard deviation or number (\%). HBV, Hepatitis $B$ virus, $\mathrm{HBeAg}$, hepatitis $B$ virus e antigen; $\mathrm{HBsAg}$, hepatitis $B$ virus surface antigen; ALT, alanine transaminase; AST, aspartate transaminase; NLR, neutrophil-to-lymphocyte ratio; PLR, platelet-to-lymphocyte ratio.

\section{Results}

Basic clinicopathological characteristics. This study enrolled 71 patients who received pre-treatment clinical evaluation including liver biopsy before peginterferon treatment. Posttreatment WBC differential count data were also collected. Baseline clinicopathological characteristics and post-treatment WBC differential count data are shown in Table I. As expected, male patients were predominant (male/female $=84.5 \% / 15.5 \%$ ). There were $15(21.1 \%)$ patients with liver cirrhosis. Ishak histology activity index was $3.01 \pm 1.43$. In view of the virological data, 49 (69\%) patients were positive for $\mathrm{HBeAg}$; 
Le et al: Predictors for NLR Change After Peginterferon Treatment

Table II. Changes of white blood cell (WBC) differential counts before and after peginterferon treatment.

\begin{tabular}{lcccc}
\hline Parameter & Pre-treatment & Post-treatment & Difference & $p$-Value \\
\hline Total WBC, $/ \mu \mathrm{l}$ & $5697.18 \pm 1541.98$ & $5660.00 \pm 1301.44$ & $-60.00 \pm 1422.84$ & 0.725 \\
Neutophil count, $/ \mu \mathrm{l}$ & $2919.82 \pm 1005.35$ & $2976.69 \pm 846.47$ & $56.87 \pm 944.41$ & 0.613 \\
Lymphocyte count, $/ \mu \mathrm{l}$ & $2209.55 \pm 766.86$ & $2114.87 \pm 732.35$ & $-94.67 \pm 702.97$ & 0.260 \\
Neutrophil percentage, $\%$ & $51.05 \pm 8.92$ & $52.92 \pm 9.36$ & $1.88 \pm 8.82$ & 0.077 \\
Lymphocyte percentage, $\%$ & $38.91 \pm 8.57$ & $37.32 \pm 8.70$ & $-1.58 \pm 8.43$ & 0.118 \\
NLR & $1.44 \pm 0.63$ & $1.58 \pm 0.78$ & $0.14 \pm 0.73$ & 0.103 \\
PLR & $100.00 \pm 38.22$ & $102.14 \pm 46.07$ & $2.136 \pm 44.76$ & 0.689 \\
\hline
\end{tabular}

Data are presented as mean value \pm standard deviation. NLR, Neutrophil-to-lymphocyte ratio; PLR, platelet-to-lymphocyte ratio.

the mean \pm SD $\log _{10}$ HBV DNA was $7.09 \pm 1.34 \mathrm{IU} / \mathrm{ml}$, and $\log _{10}$ HBsAg was $3.65 \pm 0.88 \mathrm{IU} / \mathrm{ml}$. Two $(2.8 \%)$ patients developed $\mathrm{HCC}$ during the later follow-up periods after treatment.

Changes of WBC differential counts between pre-treatment and one year after peginterferon treatment. When the WBC differential counts data were compared for the whole study group, before and one year after peginterferon treatment, no statistical significance was found in total WBC count, neutrophil count, lymphocyte count, neutrophil percentage, lymphocyte percentage, NLR and PLR (Table II). This result indicated that no single directional change of WBC parameters were found after peginterferon treatment.

We further analyzed the factors associated with posttreatment NLR by use of regression analysis (Table III). In univariate regression analysis, age (beta $=-0.020 ; 95 \%$ $\mathrm{CI}=-0.039-0.000 ; \quad p=0.047)$ and pre-treatment NLR (beta $=0.682 ; 95 \% \mathrm{CI}=0.277-1.087 ; p=0.001$ ) were significantly associated with post-treatment NLR. In multivariate regression analysis, only pre-treatment NLR was independently associated with post-treatment NLR (beta $=-0.262 ; 95 \% \mathrm{CI}=-0.445$ $-0.078 ; p=0.006)$. Intriguingly, pre-treatment NLR and posttreatment NLR were negatively correlated.

Clinical parameters associated with NLR changes before and after peginterferon treatment. Because of the interesting finding that the pre-treatment NLR was negatively associated with post-treatment NLR in regression analysis, we subsequently analyzed other clinical factors associated with NLR changes ( $\triangle N L R)$ before and after peginterferon treatment. When NLR remained the same or increased, $\triangle$ NLR would be $\geq 0$, whereas when NLR decreased, $\triangle N L R$ would be $<0$. Logistic regression analysis was, thus, performed accordingly (Table IV).

For better clinical application, when a continuous variable had a value of $p<0.3$, we also included this variable as a dichotomous variable for further analysis. The cut-off point was decided by a ROC curve with Youden index. In this way, we found the $p$-values of $\log _{10} \operatorname{HBV}$ DNA $(p=0.251)$,
Table III. Regression analysis of the clinical factors associated with post-treatment neutrophil-to-lymphocyte ratio (NLR).

\begin{tabular}{lccc}
\hline Characteristic & $\begin{array}{c}\text { Regression } \\
\text { coefficient }\end{array}$ & $95 \%$ CI & $p$-Value \\
& & & \\
\hline Univariate analysis & -0.020 & $-0.039-0.000$ & $\mathbf{0 . 0 4 7}$ \\
Age, years & 0.110 & $-0.538-0.758$ & 0.734 \\
Gender, male & 0.432 & $-0.774-1.639$ & 0.474 \\
Hepatocellular carcinoma & 0.028 & $-0.922-0.977$ & 0.953 \\
Cirrhosis & -0.009 & $-0.313-0.295$ & 0.952 \\
Ishak histology activity index & 0.168 & $-0.477-0.812$ & 0.603 \\
Piecemeal necrosis (score>1) & -0.309 & $-1.138-0.520$ & 0.457 \\
Confluent necrosis (score>0) & & & \\
Focal (spotty) lytic necrosis, & & & \\
$\quad$ apoptosis, and focal & & & \\
$\quad$ inflammation (score>2) & 0.169 & $-0.448-0.786$ & 0.584 \\
Portal inflammation (score>2) & 0.029 & $-0.451-0.510$ & 0.902 \\
Viral serologic analysis & & & \\
HBV DNA load, log10 IU/ml & 0.027 & $-0.224-0.278$ & 0.832 \\
HBeAg positive & -0.030 & $-0.574-0.514$ & 0.911 \\
HBsAg level, log IU/ml & -0.121 & $-0.515-0.274$ & 0.542 \\
Serum biochemistry analysis & & & \\
ALT, IU/l & $-1.711 \times 10^{-5}$ & $-0.004-0.004$ & 0.993 \\
AST, IU/l & -0.001 & $-0.008-0.005$ & 0.662 \\
Bilirubin, mg/dl & 0.014 & $-0.644-0.671$ & 0.966 \\
Platelet count, $\times 1000 / m m 3$ & -0.001 & $-0.007-0.005$ & 0.738 \\
Hemoglobin, g/dl & -0.106 & $-0.291-0.080$ & 0.257 \\
Pre-treatment NLR & 0.682 & $0.277-1.087$ & $\mathbf{0 . 0 0 1}$ \\
Pre-treatment PLR & 0.000 & $-0.008-0.007$ & 0.938 \\
Multivariate analysis & & & \\
Age, years & 0.004 & $-0.007-0.015$ & 0.473 \\
Pre-treatment NLR & -0.262 & $-0.445-0.078$ & $\mathbf{0 . 0 0 6}$ \\
\hline
\end{tabular}

CI, Confidence interval; HBV, hepatitis B virus; $\mathrm{HBeAg}$, hepatitis B virus e antigen; $\mathrm{HBsAg}$, hepatitis $B$ virus surface antigen; ALT, alanine transaminase; AST, aspartate transaminase; GGT; NLR, neutrophil-tolymphocyte ratio; PLR, platelet-to-lymphocyte ratio. Significant $p$ values are shown in bold.

$\log _{10} \mathrm{HBsAg}(p=0.144), \mathrm{Hb}(p=0.104)$ and pre-treatment NLR ( $p=0.013$ ) were below 0.3 . The optimal cutoffs of these parameters were obtained to transform them into dichotomous variables (optimal cutoffs=7.905 IU/ml, 4.01 
Table IV. Univariate and multivariate analysis of the clinical factors associated with increasing neutrophil-to-lymphocyte ratio (NLR) after peginterferon treatment.

\begin{tabular}{|c|c|c|c|}
\hline Characteristic & Odd ratio & $95 \% \mathrm{CI}$ & $p$-Value \\
\hline \multicolumn{4}{|l|}{ Univariate analysis } \\
\hline Age, years & 1.007 & $0.962-1.054$ & 0.773 \\
\hline Gender, male & 0.698 & $0.185-2.640$ & 0.597 \\
\hline Hepatocellular carcinoma & 0.769 & $0.046-12.807$ & 0.855 \\
\hline Cirrhosis & 0.995 & $0.324-3.058$ & 0.994 \\
\hline Ishak histology activity index & 1.042 & $0.748-1.451$ & 0.809 \\
\hline Piecemeal necrosis (score $>1$ ) & 2.710 & $0.666-11.021$ & 0.164 \\
\hline Confluent necrosis $($ score $>0)$ & 0.547 & $0.113-2.649$ & 0.454 \\
\hline Focal (spotty) lytic necrosis, apoptosis, and focal inflammation (score $>2$ ) & 1.733 & $0.525-5.727$ & 0.367 \\
\hline Portal inflammation (score $>2$ ) & 1.645 & $0.628-4.307$ & 0.311 \\
\hline \multicolumn{4}{|l|}{ Viral serologic analysis } \\
\hline HBV DNA load, $\log _{10}$ & 0.803 & $0.551-1.168$ & 0.251 \\
\hline HBV DNA load, $\log _{10} \geq 7.905 \mathrm{IU} / \mathrm{ml}$ & 0.460 & $0.163-1.295$ & 0.141 \\
\hline HBeAg positive & 0.521 & $0.179-1.513$ & 0.230 \\
\hline HBsAg, $\log _{10}$ & 0.654 & $0.370-1.156$ & 0.144 \\
\hline $\mathrm{HBsAg}, \log _{10} \geq 4.01 \mathrm{IU} / \mathrm{ml}$ & 0.356 & $0.132-0.956$ & 0.040 \\
\hline \multicolumn{4}{|l|}{ Serum biochemistry analysis } \\
\hline ALT, IU/1 & 1.001 & $0.997-1.005$ & 0.594 \\
\hline AST, IU/1 & 1.000 & $0.994-1.006$ & 0.943 \\
\hline Bilirubin, mg/dl & 1.262 & $0.237-6.731$ & 0.785 \\
\hline Platelet count, $\times 1,000 / \mathrm{mm}^{3}$ & 0.999 & $0.988-1.009$ & 0.793 \\
\hline Hemoglobin & 0.738 & $0.511-1.064$ & 0.104 \\
\hline Hemoglobin, $\geq 15.65 \mathrm{~g} / \mathrm{dl}$ & 0.313 & $0.114-0.853$ & 0.023 \\
\hline Pre-treatment NLR & 0.320 & $0.130-0.783$ & 0.013 \\
\hline Pre-treatment NLR $\geq 1.39$ & 0.265 & $0.098-0.712$ & 0.008 \\
\hline Pre-treatment PLR & 0.988 & $0.976-1.001$ & 0.076 \\
\hline \multicolumn{4}{|l|}{ Multivariate analysis } \\
\hline $\mathrm{HBsAg}, \log _{10} \geq 4.01 \mathrm{IU} / \mathrm{ml}$ & 0.253 & $0.074-0.863$ & 0.028 \\
\hline Hemoglobin, $\geq 15.65 \mathrm{~g} / \mathrm{dl}$ & 0.170 & $0.049-0.585$ & 0.005 \\
\hline Pre-treatment NLR $\geq 1.39$ & 0.290 & $0.096-0.877$ & 0.028 \\
\hline
\end{tabular}

CI, Confidence interval; HBV, hepatitis B virus; $\mathrm{HBeAg}$, hepatitis B virus e antigen; HBsAg, hepatitis B virus surface antigen; ALT, alanine transaminase; AST, aspartate transaminase; PLR, platelet-to-lymphocyte ratio. When continuous variables had a $p$-value $<0.3$, it was assessed as a nominal variable for further analysis according to optimal cut-off point decided by receiver operating characteristic curve with Youden index.

IU/1, $15.65 \mathrm{~g} / \mathrm{dl}$, and 1.39, respectively). The obviously opposing trends of $\triangle \mathrm{NLR}$ were observed in patients portioned by NLR (Figure 1).

As such, it was found that $\log _{10} \mathrm{HBs} \mathrm{Ag} \geq 4.01 \mathrm{IU} / \mathrm{ml}$ $(\mathrm{OR}=0.356 ; 95 \% \mathrm{CI}=0.132-0.956 ; p=0.040)=\mathrm{Hb} \geq 15.65 \mathrm{~g} / \mathrm{dL}$ $(\mathrm{OR}=0.313 ; 95 \%$ CI $0.114-0.853 ; p=0.023)$ and pre-treatment $\mathrm{NLR} \geq 1.39(\mathrm{OR}=0.265 ; 95 \% \mathrm{CI}=0.098-0.712 ; p=0.008)$ were significantly associated with binary NLR change in univariate analysis. In multivariate analysis, it was found that these were all independent factors: $\log _{10} \mathrm{HBsAg} \geq 4.01 \mathrm{IU} / \mathrm{ml}: \mathrm{OR}=0.253$, 95\% $\mathrm{CI}=0.074-0.863$, adjusted $p=0.028 ; \mathrm{Hb} \geq 15.65 \mathrm{~g} / \mathrm{dl}$ : $\mathrm{OR}=0.170,95 \% \mathrm{CI}=0.049-0.585$, adjusted $p=0.028$; and pretreatment $\mathrm{NLR} \geq 1.39$ : $\mathrm{OR}=0.290,95 \% \quad \mathrm{CI}=0.096-0.877$, adjusted $p=0.028$.

A predictive score (PS) was thus formulated: $\mathrm{PS}=2.095$ 1.237×pre-treatment NLR_b $-1.774 \times$ HB_b $-1.373 \times \operatorname{logHBs}$ Ag_b, where NLR_b=1 if NLR $\geq 1.39$, otherwise 0 ; HB_b=1 if $\mathrm{Hb} \geq 15.65 \mathrm{~g} / \mathrm{dL}$, otherwise $0 ; \log H \mathrm{BsAg} \_\mathrm{b}=1$ if $\log$ HBsAg $10 \geq 4.01 \mathrm{IU} / \mathrm{ml}$, otherwise 0 .

When this score was used to predict $\triangle \mathrm{NLR}$, an AUC of $76.5 \%$ and optimal cutoff of 0.5 were obtained $(\mathrm{OR}=101.746 ; 95 \% \mathrm{CI}=8.701-1189.725 ; p<0.001)$ (Figures 2 and 3). The only two HCC cases developed at 20 and 80 months after completing peginterferon treatment, with predictive scores of 0.89 and 0.70 , both above the cutoff of 0.5 , which predicted an increase of NLR.

\section{Discussion}

Several studies had established that a higher NLR was independently associated with early mortality and poor clinical outcomes of HBV-related decompensated liver cirrhosis, resectable and advanced $\mathrm{HCC}$ after treatments (radical hepatectomy, radiofrequency ablation, transarterial chemo- 


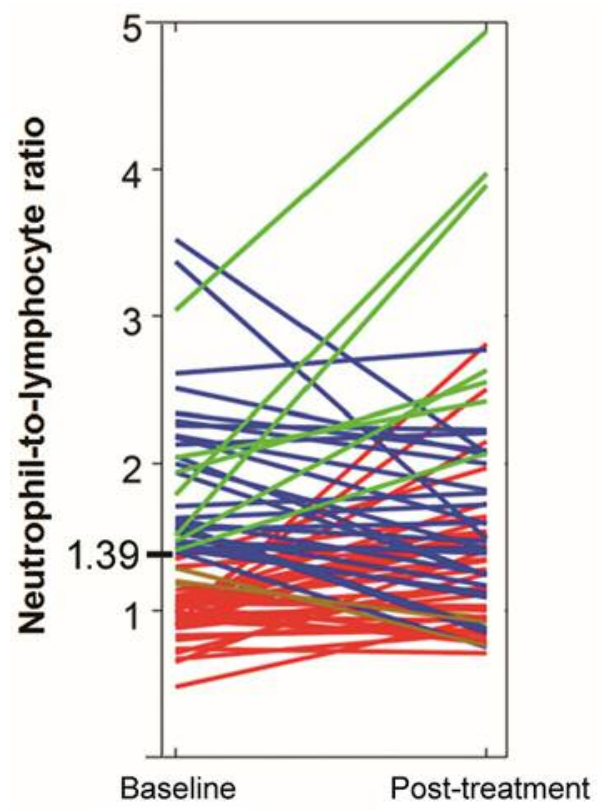

Figure 1. Negative association between pretreatment neutrophil-tolymphocyte ratio $(N L R)$ and NLR changes in patients before and after peginterferon treatment. Of 33 patients with pre-treatment $N L R \geq 1.39$, 26 had either no prominent change of $N L R(\triangle N L R=-0.25$ to 0.25$)$ or a substantial decrease $(\triangle N L R<-0.25)$ of $N L R$ after peginterferon treatment (blue lines); whereas only seven patients had a substantial increase of $N L R(\triangle N L R>0.25)$ (green lines). On the other hand, of 38 patients with $N L R<1.39,35$ had either no prominent change of NLR or a substantial increase $(\triangle N L R>0.25)$ of $N L R$ (red lines); whereas only three had a substantial decrease of $N L R(\triangle N L R<-0.25)$ (brown lines).

embolization, liver transplantation) (31-35). Our recent analysis revealed that peginterferon was superior to nucleos(t)ide in reducing HCC risk (9), and immunomo-dulation may play a significant role. However, the actual immunomodulatory properties linked to the anti-HCC effects were poorly understood. In the present study, a novel and intriguing result was found. The pre-treatment NLR was, in fact, negatively associated with the NLR change before and after peginterferon treatment. Accordingly, patients with chronic hepatitis B with higher pretreatment NLRs were likely to benefit from peginterferon treatment, in terms of HCC prevention.

At this time, the mechanism by which peginterferon negatively regulates NLR is not clear. Conceivably, the NLR is determined by the balance between the rates of neurophils/ lymphocytes generation and damage. Myelopoiesis occurrs in bone marrow through multiple steps, which are regulated through several cellular and humoral factors not fully characterized (36). Lymphopoiesis involves even more organs from bone marrow to lymphoid tissues, with several complex developmental steps (37). On the other hand, it is clear that lymphocytes play a major role in HBV-related

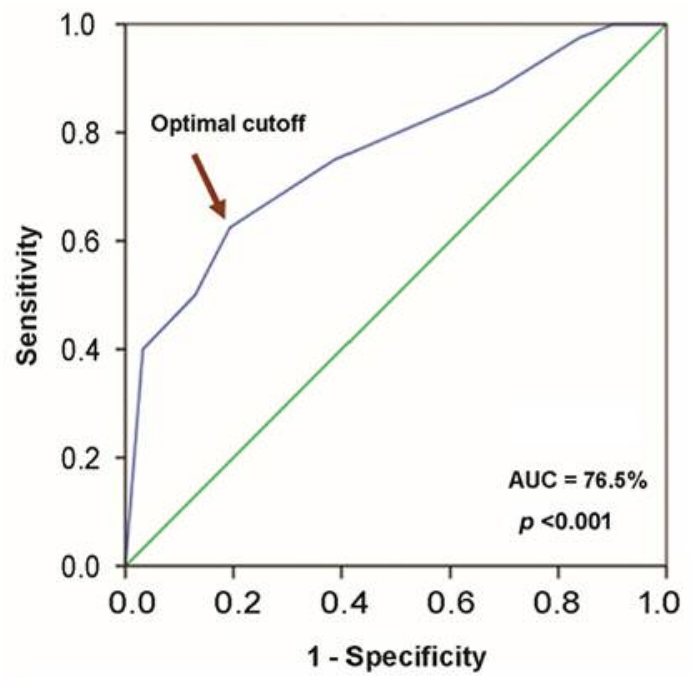

Figure 2. The performance of the predictive score in prediction of neutrophil-to-lymphocyte ratio (NLR) changes assessed by the receiver operating characteristic curve. The optimum cutoff of the predictive score was 0.5 with sensitivity of 0.625 and specificity of 0.806 . AUC: Area under the curve.

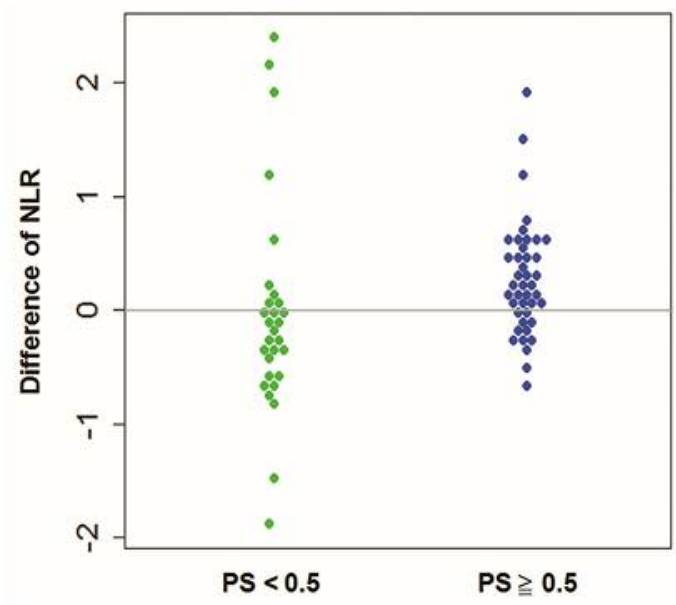

Figure 3. The scatterplot of difference in neutrophil-to-lymphocyte ratio $(N L R)$ in patients with a predictive score $(P S)$ of $<0.5$ or $\geq 0.5$.

chronic hepatitis. Infiltration of lymphocytes in the liver lobules was associated with the severity of hepatic inflammation (38). Peginterferon presumably modulated one or more of these processes so that the NLR was changed.

Other factors related to NLR changes included the HBsAg level and $\mathrm{Hb}$ level. Again, these were negatively associated with NLR changes. Presumably, higher HBsAg levels are associated with a larger amount of intrahepatic covalently 
closed circular DNA (39), and therefore an increase of hepatitis activities is more likely to occur after peginterferon treatment. Under such circumstance, an increased rate of lymphopoiesis could be expected and thus a decreased NLR. On the other hand, anemia is a well-known side-effect of interferon therapy since interferons are potent inhibitors of erythropoiesis (40). Anemia might lead to greater tissue hypoxemia and thus more damage to inflammatory liver tissues and infiltrating lymphocytes. A higher $\mathrm{Hb}$ level could provide more oxygen to tissue, resulting in a protective effect. However, the link between less hypoxemia and a decrease in NLR remains to be established.

Finally, we were able to establish a scoring system to predict NLR increase or decrease using these three factors. Interestingly, the two patients who eventually developed HCC both had a score $>0.5$, which predicted an increase of NLR after peginterferon treatment, and thus an increased risk of HCC. These data imply that the predictive score might be used to select patients who could benefit more (in terms of HCC prevention) when choosing between peginterferon and nucleos(t)ide analogs as anti-HBV therapy.

\section{Conclusion}

The pre-treatment NLR, $\mathrm{Hb}$ and HBsAg level, in combination, formulated a score which effectively predicts NLR change after peginterferon treatment in patients with chronic hepatitis B. Accordingly, it may be possible to select patients who would benefit most from peginterferon treatment in prevention of HCC.

\section{References}

1 Maynard JE: Hepatitis b: Global importance and need for control. Vaccine 8 Suppl: S18-20, 1990.

2 Ott JJ, Stevens GA, Groeger J and Wiersma ST: Global epidemiology of hepatitis b virus infection: New estimates of age-specific HBsAg seroprevalence and endemicity. Vaccine 30(12): 2212-2219, 2012.

3 Lok AS: Hepatitis b: Liver fibrosis and hepatocellular carcinoma. Gastroenterol Clin Biol 33(10-11): 911-915, 2009.

4 Tsukuma H, Hiyama T, Tanaka S, Nakao M, Yabuuchi T, Kitamura T, Nakanishi K, Fujimoto I, Inoue A, Yamazaki H and Kawashima T: Risk factors for hepatocellular carcinoma among patients with chronic liver disease. N Engl J Med 328(25): 1797-1801, 1993.

5 Lim SG, Mohammed R, Yuen MF and Kao JH: Prevention of hepatocellular carcinoma in hepatitis $\mathrm{b}$ virus infection. $\mathrm{J}$ Gastroenterol Hepatol 24(8): 1352-1357, 2009.

6 Lai CL and Yuen MF: Prevention of hepatitis B virus-related hepatocellular carcinoma with antiviral therapy. Hepatology 57(1): 399-408, 2013.

7 Lin SM, Yu ML, Lee CM, Chien RN, Sheen IS, Chu CM and Liaw YF: Interferon therapy in $\mathrm{HBeAg}$-positive chronic hepatitis reduces progression to cirrhosis and hepatocellular carcinoma. $\mathrm{J}$ Hepatol 46(1): 45-52, 2007.
8 Liaw YF, Sung JJ, Chow WC, Farrell G, Lee CZ, Yuen H, Tanwandee T, Tao QM, Shue K, Keene ON, Dixon JS, Gray DF and Sabbat J: Lamivudine for patients with chronic hepatitis B and advanced liver disease. N Engl J Med 351(15): 1521-1531, 2004.

9 Liang KH, Hsu CW, Chang ML, Chen YC, Lai MW and Yeh CT: Peginterferon is superior to nucleos(t)ide analogues for prevention of hepatocellular carcinoma in chronic hepatitis B. J Infect Dis 213(6): 966-974, 2016.

10 Yeh CT, Chen T, Hsu CW, Chen YC, Lai MW, Liang KH and Chen TC: Emergence of the rtA181T/SW 172* mutant increased the risk of hepatoma occurrence in patients with lamivudineresistant chronic hepatitis B. BMC Cancer 11: 398, 2011.

11 Lai MW, Liang KH, Lin WR, Huang YH, Huang SF, Chen TC and Yeh CT: Hepatocarcinogenesis in transgenic mice carrying hepatitis B virus pre-s/s gene with the sw172* mutation. Oncogenesis 5(12): e273, 2016.

12 Boccia A, Virata C, Lindner D, English N, Pathan N, Brickelmaier M, Hu X, Gardner JL, Peng L, Wang X, Zhang X, Yang L, Perron K, Yco G, Kelly R, Gamez J, Scripps T, Bennett D, Joseph IB and Baker DP: Peginterferon beta-1a shows antitumor activity as a single agent and enhances efficacy of standard of care cancer therapeutics in human melanoma, breast, renal, and colon xenograft models. J Interferon Cytokine Res 37(1): 20-31, 2017.

13 Barash H, E RG, Edrei Y, Ella E, Israel A, Cohen I, Corchia N, Ben-Moshe T, Pappo O, Pikarsky E, Goldenberg D, Shiloh Y, Galun E and Abramovitch R: Accelerated carcinogenesis following liver regeneration is associated with chronic inflammation-induced double-strand DNA breaks. Proc Natl Acad Sci USA 107(5): 2207-2212, 2010.

14 Chen L, Zhang Q, Chang W, Du Y, Zhang H and Cao G: Viral and host inflammation-related factors that can predict the prognosis of hepatocellular carcinoma. Eur J Cancer 48(13): 1977-1987, 2012.

15 Budhu A, Forgues M, Ye QH, Jia HL, He P, Zanetti KA, Kammula US, Chen Y, Qin LX, Tang ZY and Wang XW: Prediction of venous metastases, recurrence, and prognosis in hepatocellular carcinoma based on a unique immune response signature of the liver microenvironment. Cancer Cell 10(2): 99$111,2006$.

16 Schreiber RD, Old LJ and Smyth MJ: Cancer immunoediting: Integrating immunity's roles in cancer suppression and promotion. Science 331(6024): 1565-1570, 2011.

17 Ji WH, Jiang YH, Ji YL, Li B and Mao WM: Prechemotherapy neutrophil: Lymphocyte ratio is superior to the platelet: lymphocyte ratio as a prognostic indicator for locally advanced esophageal squamous cell cancer treated with neoadjuvant chemotherapy. Dis Esophagus 29(5): 403-411, 2016.

$18 \mathrm{Wu} \mathrm{J}$, Chen M, Liang C and Su W: Prognostic value of the pretreatment neutrophil-to-lymphocyte ratio in cervical cancer: A meta-analysis and systematic review. Oncotarget, 2017. doi: 10.18632/oncotarget.14541. [Epub ahead of print]

19 Vartolomei MD, Mathieu R, Margulis V, Karam JA, Roupret M, Lucca I, Mbeutcha A, Seitz C, Karakiewicz PI, Fajkovic H, Wood CG, Weizer AZ, Raman JD, Rioux-Leclercq N, Haitel A, Bensalah K, Rink M, Briganti A, Xylinas E and Shariat SF: Promising role of preoperative neutrophil-to-lymphocyte ratio in patients treated with radical nephroureterectomy. World J Urol 35(1): 121-130, 2017. 
20 Ertas IE, Gungorduk K, Akman L, Ozdemir A, Terek MC, Ozsaran A, Sanci $M$ and Dikmen Y: Can preoperative neutrophil:lymphocyte and platelet:lymphocyte ratios be used as predictive markers for lymph node metastasis in squamous cell carcinoma of the vulva? Eur J Obstet Gynecol Reprod Biol 171(1): 138-142, 2013

21 Potretzke A, Hillman L, Wong K, Shi F, Brower R, Mai S, Cetnar JP, Abel EJ and Downs TM: NLR is predictive of upstaging at the time of radical cystectomy for patients with urothelial carcinoma of the bladder. Urol Oncol 32(5): 631-636, 2014

22 Templeton AJ, McNamara MG, Seruga B, Vera-Badillo FE, Aneja P, Ocana A, Leibowitz-Amit R, Sonpavde G, Knox JJ, Tran B, Tannock IF and Amir E: Prognostic role of neutrophilto-lymphocyte ratio in solid tumors: A systematic review and meta-analysis. J Natl Cancer Inst 106(6): dju124, 2014.

23 Buttigliero C, Pisano C, Tucci M, Vignani F, Bertaglia V, Iaconis D, Guglielmini P, Numico G, Scagliotti GV and Di Maio M: Prognostic impact of pretreatment neutrophil-to-lymphocyte ratio in castration-resistant prostate cancer patients treated with first-line docetaxel. Acta Oncol 56(4): 555-562, 2017.

24 Xue TC, Zhang L, Xie XY, Ge NL, Li LX, Zhang BH, Ye SL and Ren ZG: Prognostic significance of the neutrophil-tolymphocyte ratio in primary liver cancer: A meta-analysis. PLoS One 9(5): e96072, 2014.

25 Li X, Chen ZH, Ma XK, Chen J, Wu DH, Lin Q, Dong M, Wei L, Wang TT, Ruan DY, Lin ZX, Xing YF, Deng Y, Wu XY and Wen JY: Neutrophil-to-lymphocyte ratio acts as a prognostic factor for patients with advanced hepatocellular carcinoma. Tumour Biol 35(11): 11057-11063, 2014.

26 Gardini AC, Scarpi E, Faloppi L, Scartozzi M, Silvestris N, Santini D, de Stefano G, Marisi G, Negri FV, Foschi FG, Valgiusti M, Ercolani $G$ and Frassineti GL: Immune inflammation indicators and implication for immune modulation strategies in advanced hepatocellular carcinoma patients receiving sorafenib. Oncotarget 7(41): 67142-67149, 2016.

27 Ishak K, Baptista A, Bianchi L, Callea F, De Groote J, Gudat F, Denk H, Desmet V, Korb G, MacSween RN, Phillips J, Portmann BG, Poulsen H, Scheuer PJ, Schmid M and Thaler H: Histological grading and staging of chronic hepatitis. J Hepatol 22(6): 696-699, 1995.

28 Sutcliffe RP, Antoniades CG, Deshpande R, Tucker ON and Heaton N: Liver and Pancreatobiliary Surgery: With Liver Transplantation. Oxford: Oxford University Press, pp. 1-336, 2010.

29 Bruix J and Sherman M: Management of hepatocellular carcinoma. Hepatology 42(5): 1208-1236, 2005.

30 Liaw YF, Kao JH, Piratvisuth T, Chan HL, Chien RN, Liu CJ, Gane E, Locarnini S, Lim SG, Han KH, Amarapurkar D, Cooksley G, Jafri W, Mohamed R, Hou JL, Chuang WL, Lesmana LA, Sollano JD, Suh DJ and Omata M: Asian-Pacific Consensus Statement on the management of chronic hepatitis b: A 2012 update. Hepatol Int 6(3): 531-561, 2012.

31 Zhang H, Sun Q, Mao W, Fan J and Ye B: Neutrophil-tolymphocyte ratio predicts early mortality in patients with HBVrelated decompensated cirrhosis. Gastroenterol Res Pract 2016 : 4394650, 2016.
32 Zhou D, Liang J, Xu LI, He F, Zhou Z, Zhang Y and Chen M: Derived neutrophil to lymphocyte ratio predicts prognosis for patients with $\mathrm{HBV}$-associated hepatocellular carcinoma following transarterial chemoembolization. Oncol Lett 11(5): 2987-2994, 2016.

33 Tajiri K, Baba H, Kawai K, Minemura M, Yasumura S, Takahara $\mathrm{T}$ and Sugiyama T: Neutrophil-to-lymphocyte ratio predicts recurrence after radiofrequency ablation in hepatitis B virus infection. J Gastroenterol Hepatol 31(7): 1291-1299, 2016.

34 Zhou DS, Xu L, Luo YL, He FY, Huang JT, Zhang YJ and Chen MS: Inflammation scores predict survival for hepatitis B virusrelated hepatocellular carcinoma patients after transarterial chemoembolization. World J Gastroenterol 21(18): 5582-5590, 2015.

35 Fu SJ, Shen SL, Li SQ, Hua YP, Hu WJ, Liang LJ and Peng BG: Prognostic value of preoperative peripheral neutrophil-tolymphocyte ratio in patients with $\mathrm{HBV}$-associated hepatocellular carcinoma after radical hepatectomy. Med Oncol 30(4): 721, 2013.

36 Boettcher S and Manz MG: Sensing and translation of pathogen signals into demand-adapted myelopoiesis. Curr Opin Hematol 23(1): 5-10, 2016.

37 Hirose J, Kouro T, Igarashi H, Yokota T, Sakaguchi N and Kincade PW: A developing picture of lymphopoiesis in bone marrow. Immunol Rev 189: 28-40, 2002.

38 Ye B, Liu X, Li X, Kong H, Tian L and Chen Y: T-Cell exhaustion in chronic hepatitis B infection: Current knowledge and clinical significance. Cell Death Dis 6: e1694, 2015.

39 Chan HL, Thompson A, Martinot-Peignoux M, Piratvisuth T, Cornberg M, Brunetto MR, Tillmann HL, Kao JH, Jia JD, Wedemeyer H, Locarnini S, Janssen HL and Marcellin P: Hepatitis B surface antigen quantification: Why and how to use it in 2011 - a core group report. J Hepatol 55(5): 1121-1131, 2011.

40 Espinosa M, Arenas MD, Aumente MD, Barril G, Buades JM, Aviles B, Carretero D, Alvarez-Lara MA, Carnicer F, MartinMalo A and Aljama P: Anemia associated with pegylated interferon-alpha2a and alpha2b therapy in hemodialysis patients. Clin Nephrol 67(6): 366-373, 2007.
Received March 8, 2017

Revised April 10, 2017

Accepted April 11, 2017 